\title{
O fenômeno da coopetição em arranjos produtivos locais: uma análise sob diferentes abordagens
}

\author{
The coopetition phenomenon in local productive arrangements: \\ an analysis under different approaches
}

Luis André Wernecke Fumagallii ${ }^{[a]}$, Cristiano Molinari Bispo ${ }^{[b]}$ Fernando Antonio Prado Gimenez ${ }^{[c]}$

[a] Doutorando em Administração pela Universidade Católica do Paraná (PUCPR), professor da Pontifícia Universidade Católica do Paraná (PUCPR), Curitiba, PR - Brasil, e-mail: lawfumagalli@gmail.com

[b] Doutorando em Administração pela Universidade Católica do Paraná (PUCPR), professor da Faculdade Estadual de Ciências e Letras de Campo Mourão (FACILCAM), Curitiba, PR - Brasil, e-mail: cristianobispo@uol.com.br

[c] Doutor em Doctoral Programme pela University of Manchester, professor titular da Pontifícia Universidade Católica do Paraná (PUCPR), Curitiba, PR - Brasil, e-mail: fernando.gimenez@pucpr.br

\section{Resumo}

A natureza da competição entre empresas dos mais diversos setores da economia tem sofrido modificações nos últimos anos e, dentre as suas implicações, destaca-se a necessidade da criação de alianças estratégicas para, no mínimo, manter os níveis de faturamento e, se possível, ampliá-los. Os novos cenários competitivos globalizados passaram a ser dominados pelas economias de escala, sufocando as pequenas empresas que permaneceram atadas a custos fixos muito elevados. Recentemente, os micros e pequenos empresários têm buscado formar alianças entre si para se equipararem com os grandes players com relação à eficiência em custos e nos demais benefícios da economia de escala. Essas alianças se manifestam de diversas formas: desde a afiliação informal na qual empresas demonstram interesses similares e algumas vezes boa fé para suportarem-se mutuamente, até relações contratuais mais desenvolvidas e integradas como as joint ventures. 0 principal objetivo deste ensaio é propor uma análise do fenômeno da coopetição (competição e cooperação de forma simultânea) em arranjos produtivos locais (APLs) a partir da perspectiva das configurações, essencialmente protagonizada por Miller (1987). A market-based view (MBV) e a resource-based view (RBV) são adicionadas à discussão para auxiliar a compreensão da origem da vantagem competitiva das organizações, esta última eminentemente a partir da tipologia de Greene, Brush e Brown (1997) e do conceito de construção da base de recursos de Brush, Greene e Hart (2001). Essa conclusão se consegue com a observação dessa discussão é que o alto grau de configuração pode resultar em uma série de vantagens sobre os seguintes pontos: sinergia, clareza de direção e coordenação, dificuldade de imitação, competência distintiva, comprometimento, velocidade e economia.

Palavras-chave: Coopetição. Market-based view. Resource-based view. Abordagem das configurações. 


\begin{abstract}
The nature of competition between companies of different sectors of the economy has undergone changes in recent years and, among its implications, there is the need to create strategic alliances to at least maintain levels of income and, if possible, extend them. The new globalized competitive scenarios come to be dominated by economies of scale, stifling small businesses that remained tied to a very high fixed costs. Recently, micro and small entrepreneurs have sought to form alliances among themselves to mate with the major players in relation to cost efficiency and other benefits from economies of scale. These alliances are manifested in various forms: from informal affiliation in which companies have shown similar interests and sometimes good faith to support each other, even more developed contractual relations and integrated as joint ventures. The main purpose of this paper is to propose an analysis of the phenomenon of coopetition (competition and cooperation simultaneously) in local productive arrangements (APLS) from the perspective of settings, mainly starring Miller (1987). The market-based view (MBV) and resource-based view (RBV) are added to the discussion to aid understanding of the origin of competitive advantage of organizations, the latter predominantly by the type of Greene, Brush and Brown (1997) and concept of building the resource base of Brush, Greene and Hart (2001). One conclusion that can be achieved with this discussion is the observation that a high degree of configuration can result in a number of advantages over the following points: synergy, clarity of direction and coordination, difficulty of imitation, distinctive competence, commitment, speed, and economy.
\end{abstract}

Keywords: Coopetition. Market-based view. Resource-based view. Configuration approach.

\section{Introdução}

Nos mercados em constante mutação e praticamente livres de fronteiras, as organizações alcançam o sucesso por meio de produtos e serviços inovadores, desenvolvendo negócios de modo mais eficiente e rápido que seus concorrentes. Nos mercados atuais, as pequenas empresas têm enfrentado muitas dificuldades para competir com as grandes empresas transnacionais e globais que usufruem das vantagens da economia de escala. As alternativas para os pequenos empresários, até pouco tempo atrás, não eram muito animadoras: serem adquiridos pelos grandes ou eliminados do mercado. Mas surge com força, então, uma nova cultura corporativa permeada de incentivos para a colaboração entre as pequenas empresas que vão desde a troca de informações informal até alianças estratégicas contratuais de longo prazo, conferindo-lhes os recursos materiais e financeiros necessários para competir em condições de igualdade com players mais poderosos individualmente. De acordo com o contexto delimitado, este ensaio objetiva discutir de que forma a market-based view (MBV) e a resource-based view (RBV) podem, por meio da abordagem das configurações, constituir-se como teorias complementares para explicar o fenômeno da coopetição entre organizações circunscritas em arranjos produtivos locais (APLs).
A revisão de literatura procura identificar as abordagens estratégicas comuns presentes nas empresas que compõem os APLs, pois se acredita que essas características são responsáveis, em grande parte, pelo seu sucesso e crescimento contínuo, advindos da visão e da aplicação da MBV, da RBV e da abordagem das configurações. Definidas essas características, buscar-se-á entender como a coopetição se incorpora aos APLs, dando origem a uma nova estratégia, ainda pouco explorada em estudos acadêmicos e ainda menos conhecida e praticada pela maioria das pequenas empresas. A partir desse encadeamento temático, faz-se necessário, portanto, discorrer acerca de alguns conceitos pertinentes ao estudo, os quais são apresentados a seguir.

\section{Revisão da literatura}

\section{Abordagens da estratégia}

Para melhor compreender o fenômeno da coopetição no contexto dos APLs, anteriormente à apresentação desses conceitos, são expostas e discutidas três abordagens de estratégia: a MBV, a RBV e a abordagem das configurações em organizações. Makhija (2003) distingue as duas primeiras abordagens, pontuando que a RBV se baseia no argumento de que as 
firmas com maior capacidade competitiva têm mais chances de ser bem sucedidas, enquanto a MBV preconiza que é o poder de mercado que define a base para a competição. Similarmente, Mugler (2004) sintetiza que, enquanto na MBV é a indústria que força a companhia a reagir e a responder com uma estratégia apropriada, na RBV é a disponibilidade de recursos que desempenha esse papel. A abordagem das configurações, por sua vez, pressupõe que um determinado número de forças (imperativos) pode restringir as possíveis variações apresentadas pelas organizações (MILLER, 1987). Dessa forma, a revisão de literatura é construída tendo em vista três momentos distintos: o posicionamento conceitual de estratégia, o contexto de discussão e o fenômeno a ser explorado.

\section{A market-based view}

Os pressupostos da MBV são associados à economia industrial, mormente articulados sob o conceito de estratégia competitiva. Para os objetivos deste ensaio, a estratégia competitiva é tratada sob o ponto de vista de Porter (1980), com consequências sobre a vantagem competitiva (PORTER, 1985). Assim, a estratégia competitiva situa-se no nível da unidade de negócio ou no nível empresarial. Esse pressuposto auxilia a delimitar e contextualizar o ambiente no qual a concorrência se estabelece de forma mais direta. Como a estratégia competitiva envolve o pensamento organizacional no nível empresarial, a concorrência fixa-se sobre a indústria ou setor que a empresa em questão está circunscrita. Dessa forma, a análise da indústria pode ser caracterizada como uma ferramenta que antecede a elaboração de estratégias com o fim de auferir vantagem competitiva.

Porter (1980) explica que, para que uma estratégia competitiva tenha êxito, a mesma deve contemplar fatores que permitam à organização tomar uma postura defensável contra as cinco forças expostas. Para tanto, três caminhos são indicados. 0 primeiro prega o posicionamento empresarial de modo a expor e utilizar suas capacidades e assim construir sua melhor defesa. 0 segundo ponto aconselha tomar uma postura influenciadora acerca do equilíbrio das forças competitivas através de movimentos estratégicos. 0 último caminho é antecipar-se às mudanças que constituem as cinco forças e responder a elas de modo proativo.

Entretanto, a observação das forças competitivas por si só não se justifica. $\mathrm{O}$ objetivo que permeia essa análise certamente é a obtenção de desempenho acima da média. Para isso, são apresentadas três estratégias genéricas, mutuamente exclusivas (PORTER, 1980): a) liderança no custo total; b) diferenciação; e c) enfoque. As duas primeiras assumem a amplitude larga da indústria, sendo que a última tem por finalidade a exploração de um segmento da indústria.

As estratégias genéricas mostram que, a menos que seja uma característica intrínseca do mercado, a assunção de mais de uma estratégia, ou seja, uma abordagem de meio-termo pode retirar da empresa qualquer vantagem competitiva, pois as micro e pequenas empresas possuem altas restrições de recursos (WELSH; WHITE, 1981). Além disso, segundo Robinson Junior e Pearce (1984), os dirigentes das micro e pequenas empresas consideram o planejamento estratégico uma atividade muito complexa e que exige muitos recursos, tornando-se um grande empecilho, e é realizado apenas em caso de extrema necessidade, em um comportamento predominantemente defensivo e reativo de acordo com a tipologia de Miles e Snow (1978).

O fato é que cada empresa é vista como um conjunto único de recursos tangíveis e intangíveis e de aptidões que são adquiridas, desenvolvidas e expandidas ao longo do tempo. Os recursos e aptidões dessas empresas são o resultado de suas escolhas estratégicas e da alocação de recursos ao longo do tempo e que determinam as suas performances a qualquer tempo. Essa concepção leva à definição da RBV, a qual será explorada na próxima seção.

\section{A resource-based view}

Os fundamentos da RBV estabelecem suas raízes no trabalho de Penrose (1959), o qual contribuiu para a concepção da empresa como um conjunto de recursos produtivos. Tal conceito é utilizado por Rumelt (1984) e Wernerfelt (1984), os quais ensejam a construção de uma abordagem na qual as competências diferenciais das organizações são extraídas de seus recursos e capacidades, representadas por ativos tangíveis e intangíveis. Assim, na visão de Wernerfelt (1984), recurso é qualquer coisa que possa ser pensada como uma força ou uma fraqueza de determinada firma.

Especificamente em relação a Penrose (1959), essa autora desenvolve seus argumentos com vistas a identificar características nas firmas que possam 
tanto promover como limitar o ritmo de crescimento delas. Nesse sentido, a obra parte do pressuposto de que não há um tamanho ótimo para as firmas e de que os recursos internos das firmas desempenham papel fundamental para o crescimento, eminentemente pela configuração de seus serviços produtivos capazes de moldar a demanda. Não menosprezando o âmbito externo, mas apenas focando nos internos pelo fato de os primeiros serem considerados mais conhecidos, a autora citada expõe que os recursos, sejam materiais e/ ou pessoais, viabilizam a consecução de um conjunto de serviços que subsidiam as atividades produtivas. Assim, o âmago da discussão dá-se na perspectiva de que toda firma sempre possui um repositório de serviços produtivos (oriundos dos recursos) e de conhecimento que não é utilizado em sua plenitude, sendo que a explicação para isto pode ser organizada em dois flancos: o primeiro, de que sempre há uma maneira de utilizar os serviços dos recursos de uma forma mais lucrativa; e o segundo, de que alguns serviços de certos recursos podem deixar de ser utilizados plenamente, liberando-os para outros fins.

Dessa forma, os conceitos de recursos e capacidades parecem estar fortemente relacionados de maneira a configurar uma competência organizacional distintiva. Para fundamentar esse raciocínio, utilizam-se os trabalhos de Wernerfelt (1984), Grant (1991) e de Prahalad e Hamel (1990). Formalmente, novamente sob a ótica de Wernerfelt (1984), além de os recursos poderem ser definidos como ativos tangíveis e intangíveis, conforme foi indicado acima, os mesmos podem ser ligados quase permanentemente a uma empresa. Passando para a conceituação de capacidades, Grant (1991) afirma que a criação de capacidades não é simplesmente uma questão de reunir um grupo de recursos, capacidades envolvem padrões complexos de coordenação entre pessoas e entre pessoas e recursos.

De maneira complementar, Barney (1991) desenvolve seus argumentos por meio do link entre recursos de uma empresa e vantagem competitiva sustentável. Suas observações são tecidas a partir de duas premissas: (i) que os recursos estratégicos são distribuídos de maneira heterogênea entre as empresas; e (ii) que essas diferenças são estáveis ao longo do tempo. Para indicar o potencial dos recursos de uma empresa em gerar e sustentar vantagem competitiva, Barney (1991) discute quatro indicadores: o valor, a raridade, a imitabilidade e a substitutibilidade dos recursos.
Diante deste contexto, entende-se que, para que seja possível dar início às atividades de determinado negócio, faz-se necessário primeiramente identificar as necessidades vitais para a sua operacionalização. Este conceito é trabalhado por Brush, Greene e Hart (2001) nomenclaturando essa situação de construção da base de recursos. Sendo assim, tornam-se vitais para a concretização do plano de negócios a identificação, atração, combinação e transformação de recursos individuais em recursos organizacionais. Percebe-se, portanto, que a construção da base de recursos tem por finalidade, no primeiro momento, alavancar o empreendimento, viabilizando sua criação e estruturação. No segundo momento, a base de recursos passa a constituir-se num dos principais patrimônios do empreendimento, permitindo sua consolidação e crescimento. A atenção a ser dada ao processo de construção dessa base torna-se crítica para o sucesso do empreendimento (BRUSCH; GREENE; HART, 2001). Alinhada a essa concepção, Greene, Brush e Brown (1997) propõem uma classificação, envolvendo recursos humanos, sociais, físicos, organizacionais e financeiros. Esses recursos são visualizados como determinantes da razão de existir da firma, além de envolverem elementos como tamanho (porte empresarial), escopo e crescimento.

\section{A abordagem das configurações}

Para proceder à contextualização da abordagem das configurações, vale considerar inicialmente algumas ideias de Miller e Mintzberg (1985), os quais coerentemente fazem uma discussão sobre análise e síntese. Os autores citados mencionam que o estudo das organizações (e talvez das ciências sociais como um todo) tem privilegiado a análise em detrimento da síntese. A análise, especificam os autores, trabalha com relações contínuas entre poucas variáveis, normalmente na procura de relações causais. Por sua vez a síntese, a qual é advogada pelos mesmos, busca a identificação de distintas configurações que podem ser compreendidas inicialmente como aglomerados de atributos, os quais incluem estados e processos de uma dada organização, bem como características de sua situação. O Quadro 1 sumariza esses conceitos.

Entretanto, os autores referidos reconhecem que, tanto a análise como a síntese, são fases necessárias à atividade científica. A análise é usada para definir os componentes ou atributos de um fenômeno e 
Quadro 1 - Abordagem analítica e perspectiva da síntese

\begin{tabular}{|c|c|}
\hline Críticas da abordagem analítica & Perspectiva da síntese \\
\hline O foco dá-se sobre relacionamentos bivariados. & Um grande número de atributos é estudado simultaneamente. \\
\hline $\begin{array}{l}\text { Os relacionamentos são assumidos como lineares com causali- } \\
\text { dade unidirecional. }\end{array}$ & $\begin{array}{l}\text { A análise de dados e a construção de teoria são orientadas para } \\
\text { descobrir aglomerados naturais. }\end{array}$ \\
\hline $\begin{array}{l}\text { As amostras de pesquisas tendem a ser muito restritas ou } \\
\text { muito amplas. }\end{array}$ & A causalidade é observada nos termos mais amplos possíveis. \\
\hline As medidas são geralmente obtidas de um único ponto no tempo. & $\begin{array}{l}\text { O tempo e o processo são levados em consideração sempre que } \\
\text { possível. }\end{array}$ \\
\hline $\begin{array}{l}\text { As variáveis tendem a ser abstratas e as medidas tendem a ser } \\
\text { genéricas. }\end{array}$ & $\begin{array}{l}\text { Apesar dos esforços para mensurar e quantificar, dados históri- } \\
\text { cos ou do contexto organizacional são coletados para ajudar a }\end{array}$ \\
\hline $\begin{array}{l}\text { A pesquisa normalmente é desenvolvida à distância por meio } \\
\text { de questionários. }\end{array}$ & explicar as descobertas mais sistemáticas. \\
\hline
\end{tabular}

Fonte: Adaptado de MILLER; MINTZBERG, 1985.

para medi-los. Já a síntese é usada para combiná-los em imagens integradas, conceitos ou configurações, identificando padrões e estabelecendo generalizações (MILLER; MINTZBERG, 1985).

A abordagem das configurações, de acordo com Miller (1987), pressupõe que um determinado número de forças pode restringir as possíveis variações apresentadas pelas organizações. Portanto são essas forças, denominadas de imperativos, que definem as configurações, sendo estas efeitos desses. Para chegar à definição dos quatro imperativos, quais sejam, ambiente, estrutura, liderança e estratégia, três critérios foram adotados: representar um paradigma amplamente aceito da análise organizacional, ter sido demonstrado empiricamente, e teria que gerar configurações organizacionais que ocorressem repetidamente. 0 Quadro 2 apresenta as principais proposições de cada imperativo.

Uma questão que se deve destacar sobre a aplicabilidade dos imperativos descritos é a de que, embora todas as configurações sejam produtos de influências múltiplas advindas de vários fatores, frequentemente se observa a prevalência de um imperativo sobre os demais, ou ao menos de um imperativo principal posicionado como causa dos demais. Entretanto algumas configurações, essencialmente em momentos de transição, podem ser entendidas como resultado da influência de vários imperativos simultaneamente e com níveis de importância igualmente similares, percebidos como modelos híbridos (MILLER, 1987). Essa abordagem remete ao conceito de paradigma de Kuhn (2000), que desdobra a ciência em ciência normal e ciência extraordinária, sendo a primeira dentro de um dado paradigma e a última refletindo uma transição paradigmática. Entretanto cabe expor que seu foco de discussão dirige-se à ciência de forma ampla em um contexto epistemológico.

Para as pequenas firmas, em especial, o ambiente torna-se cada vez mais hostil por consequência da intensa competição e da modificação dos cenários econômicos. Para superar as dificuldades impostas por tal ambiente, as pequenas empresas passaram a buscar novas formas de alianças para, no mínimo, equipararem-se com as grandes corporações, explorar oportunidades e adquirir vantagem competitiva sustentável.

\section{O contexto dos arranjos produtivos locais}

O início da discussão sobre aglomerados produtivos pode ser creditado a Marshall (1982), o qual apresenta duas classes de economias no contexto da organização industrial: economias internas e economias externas. As economias internas referem-se aos recursos e administração destes recursos por firmas de uma dada indústria. As economias externas referem-se ao contexto do desenvolvimento da indústria como um todo, o que pode ser alcançado pela aglomeração ou concentração geográfica de empresas de porte reduzido em um mesmo ramo industrial. Quanto à formação dessas indústrias localizadas, o autor citado acima argumenta que a principal causa reside sobre as condições físicas de determinada região, como clima, solo, existência de minas e pedreiras e facilidade de acesso da região. 
Quadro 2 - Principais proposições dos imperativos

\begin{tabular}{|c|c|c|c|}
\hline Ambiente & Estrutura & Liderança & Estratégia \\
\hline $\begin{array}{l}\text { As firmas reagem aos desafios } \\
\text { externos. }\end{array}$ & $\begin{array}{l}\text { Suporta as predições da teoria } \\
\text { da burocracia e da resource } \\
\text { dependence perspective. }\end{array}$ & $\begin{array}{l}\text { Espera-se que os dirigen- } \\
\text { tes tenham uma influência } \\
\text { dominante sobre metas, } \\
\text { estratégias, estilos de decisão, } \\
\text { estruturas e mercados-alvo. }\end{array}$ & $\begin{array}{l}\text { Suporta as prescrições dos teó- } \\
\text { ricos da política de negócios e } \\
\text { da administração estratégica. }\end{array}$ \\
\hline $\begin{array}{l}\text { Ambiente influencia estra- } \\
\text { tégia e estratégia influencia } \\
\text { estrutura. }\end{array}$ & $\begin{array}{l}\text { A estrutura influencia } \\
\text { a estratégia. }\end{array}$ & $\begin{array}{l}\text { A personalidade do CEO pode } \\
\text { influenciar a estratégia, a es- } \\
\text { trutura e o ambiente tanto de } \\
\text { forma direta como por meio } \\
\text { do estabelecimento de uma } \\
\text { cultura organizacional. }\end{array}$ & $\begin{array}{l}\text { A estratégia influencia a esco- } \\
\text { Iha do ambiente e a seleção } \\
\text { da estrutura organizacional. }\end{array}$ \\
\hline $\begin{array}{l}\text { As firmas adaptam-se ao } \\
\text { ambiente. }\end{array}$ & $\begin{array}{l}\text { As firmas concentram-se em } \\
\text { seus problemas internos, } \\
\text { buscando uma conformidade } \\
\text { gerencial. }\end{array}$ & $\begin{array}{l}\text { As principais forças do impera- } \\
\text { tivo envolvem metas, motivos, } \\
\text { fantasias e estilos interpessoais } \\
\text { do CEO. }\end{array}$ & $\begin{array}{l}\text { É enfatizado o desenvolvi- } \\
\text { mento de uma estratégia de } \\
\text { produto/mercado explícita e } \\
\text { planejada. }\end{array}$ \\
\hline $\begin{array}{l}\text { Aplica-se a pequenas firmas } \\
\text { em indústria não concentra- } \\
\text { das. }\end{array}$ & $\begin{array}{l}\text { Dada a inflexibilidade, aplica- } \\
\text {-se a firmas com alto market } \\
\text { share, de grande porte, com } \\
\text { recursos excedentes e ambien- } \\
\text { te regulatório favorável. }\end{array}$ & $\begin{array}{l}\text { Aplica-se a firmas pequenas } \\
\text { com autoridade centralizada } \\
\text { por dirigentes proprietários } \\
\text { em meio a uma cultura corpo- } \\
\text { rativa homogênea. }\end{array}$ & $\begin{array}{l}\text { Aplica-se a contextos que } \\
\text { requeiram mudanças estraté- } \\
\text { gicas significativas e a firmas } \\
\text { diversificadas. }\end{array}$ \\
\hline $\begin{array}{l}\text { Mudanças que movem as } \\
\text { firmas para outro imperativo } \\
\text { podem ser causadas por ten- } \\
\text { dências oligopolísticas, porte e } \\
\text { recursos excedentes. }\end{array}$ & $\begin{array}{l}\text { O imperativo é abandonado } \\
\text { apenas quando o mercado } \\
\text { torna-se mais competitivo } \\
\text { ou instável. }\end{array}$ & $\begin{array}{l}\text { Mudanças para outro impera- } \\
\text { tivo dependem da aposenta- } \\
\text { doria do CEO, de crescimento } \\
\text { ou de aquisição da firma. }\end{array}$ & $\begin{array}{l}\text { A dissolução do imperativo } \\
\text { pode advir da necessidade } \\
\text { da firma ser mais flexível e } \\
\text { responsiva aos mercados. }\end{array}$ \\
\hline
\end{tabular}

Fonte: Adaptado de MILLER, 1987.

Outro fator importante trazido por Marshall (1982) refere-se à especialização e decorrente qualidade de produtos de determinada localidade. Esse processo desencadeia certa atratividade de operários especializados oriundos de regiões distantes ao mesmo tempo em que educa os trabalhadores locais. Assim, constituem-se algumas vantagens que uma região especializada pode apresentar. Marshall (1982) expõe que essas regiões tendem a permanecer por longos períodos de tempo em uma mesma localidade, o que favorece o compartilhamento de informações que ajudam a consolidar ainda mais a região. Exemplos disso incluem a dificuldade de manterem-se segredos e $\mathrm{o}$ aprendizado inconsciente destas informações pelas crianças. Marshall (1982) argumenta que o gap entre a concepção de uma ideia e sua efetiva utilização tende a ser pequeno dentro de regiões especializadas. Todos esses componentes acabam por atrair fornecedores de instrumentos e matérias-primas, o que reforça o próprio aglomerado.
Schmitz e Musyck (1993), no intuito de caracterizar as aglomerações setoriais, ressaltam a proximidade geográfica, a especialização setorial, a predominância de pequenas e médias empresas, a presença de colaboração e competição entre firmas, além de destacarem a presença de uma identidade sociocultural que facilita as relações entre firmas, entre empregadores e trabalhadores qualificados, etc. Esses fatores são denominados por Schmitz (1992) como eficiência coletiva, acrescentando algumas vantagens encontradas nos aglomerados setoriais, tais como: divisão do trabalho e especialização entre os pequenos produtores, aparecimento de fornecedores provedores de matéria-prima, componentes, maquinário (inclusive de segunda mão), etc. Nesse ínterim, para melhor compreender os APLs, os mesmos podem ser observados quanto à sua formação, podendo ser constituídos deliberadamente ou de forma endógena; como também em relação ao seu formato, podendo se apresentar de forma vertical ou horizontal. 
A noção geral, que dá sustentação à formação de um APL, é a de que o compartilhamento de competências entre empresas (GINSBERG; LARSEN; LOMI, 2002) acaba por criar, por exemplo, mão de obra especializada sobre o tipo de negócio, culminando no estabelecimento de uma tradição regional. A tradição configura o arcabouço técnico das competências que a região apresenta. Entretanto, os produtos que essas competências geram inevitavelmente devem estar alinhados à demanda do mercado em que os produtos do APL têm acesso com preço competitivo.

De acordo com Amato Neto (2000), a aglomeração, em relação a produtores separados, pode favorecer a obtenção de ganhos de eficiência em teor coletivo. Entretanto ainda consoante ao autor, dentro dos APLs percebem-se tanto o sucesso, quanto a decadência de empresas. Nesse ponto, a procura por soluções que exigem ação conjunta pode trazer soluções para problemas de ordem específica. Exemplos dessas ações envolvem provisão de serviços, infraestrutura e treinamento.

Nesse sentido, os APLs podem tornar-se "repositórios de habilidades específicas da indústria", as quais são acumuladas e repassadas de pessoa a pessoa, tornando-as comuns a todo o arranjo de empresas (AMATO NETO, 2000, p. 56). Esse aspecto remete à questão da competência essencial (PRAHALAD; HAMEL, 1990); entretanto com o conceito expandido, ou seja, do nível organizacional para o nível regional (do APL).

\section{O fenômeno da coopetição}

A natureza da competição entre empresas dos mais diversos setores da economia tem sofrido modificações nos últimos anos e, dentre as suas implicações, destaca-se a necessidade da criação de alianças estratégicas para, no mínimo, manter os níveis de faturamento e, se possível, ampliá-los. Os novos cenários competitivos globalizados passaram a ser dominados pelas economias de escala, sufocando as pequenas empresas que permaneceram atadas a custos fixos muito elevados. Recentemente, os micros e pequenos empresários têm buscado formar alianças entre si para equipararem-se com os grandes players com relação à eficiência em custos e nos demais benefícios da economia de escala.

Essas alianças se manifestam de diversas formas: desde a afiliação informal, na qual empresas demonstram interesses similares e algumas vezes boa-fé para suportarem-se mutuamente, até relações contratuais mais desenvolvidas e integradas como as joint ventures, nas quais duas ou mais empresas formam outra para trabalhar juntas em um projeto separado (RING; VAN DE VEN, 1994). Essas abordagens coletivas denotam um equilíbrio entre a competição e a cooperação, maior efetividade nas campanhas de marketing, amplia a competitividade no longo prazo e favorecem o sucesso na consecução dos objetivos individuais nas regiões de atuação. A revisão da literatura revelou que existem muitos termos diferentes utilizados para definir as relações e alianças entre empresas, as quais estão resumidamente apresentadas na Figura 1.

A maior parte da literatura descreve as relações interorganizacionais com foco apenas no aspecto cooperativo do relacionamento negligenciando, muitas vezes, os seus aspectos competitivos. Para Koza e Lewin (1998), na perspectiva do mercado, é a distância da atividade com relação ao cliente que determina a divisão entre as interações de competição e cooperação: empresas competem em atividades próximas aos clientes e cooperam em atividades distantes dos mesmos. De acordo com Doz (1988), é uma mudança nas prioridades estratégicas ou a perda de liderança que fazem com que as relações se tornem mais cooperativas do que competitivas.

Paradoxalmente, em ambientes competitivos e de natureza complexa, as organizações empreendedoras desenvolvem a sua habilidade de competir a partir da sua habilidade de cooperar. A fonte de vantagem competitiva dos turbulentos mercados atuais está fortemente ligada à inovação e, como inovação está associada a altos custos e riscos, isto pode ser especialmente problemático para as pequenas empresas com recursos limitados e/ou que sejam vulneráveis às descontinuidades do ambiente (PARKER, 2000). Para Gnyawali e Madhavan (2001), os mercados e os relacionamentos entre empresas tornaram-se tão variados e complexos que invalidam a abordagem neoclássica de análise da competição e cooperação. Essa visão alinha-se com a de Porter (1985), que afirma que a cadeia de valor em ambientes dinâmicos requer coordenação e cooperação entre os diferentes stakeholders, diferentemente do que acontece na indústria manufatureira, que opera em um processo mais linear, passo a passo.

Gnyawali e Madhavan (2001) argumentam que relações competitivas e cooperativas não são excludentes entre si, mas que coexistem com muita frequência. 


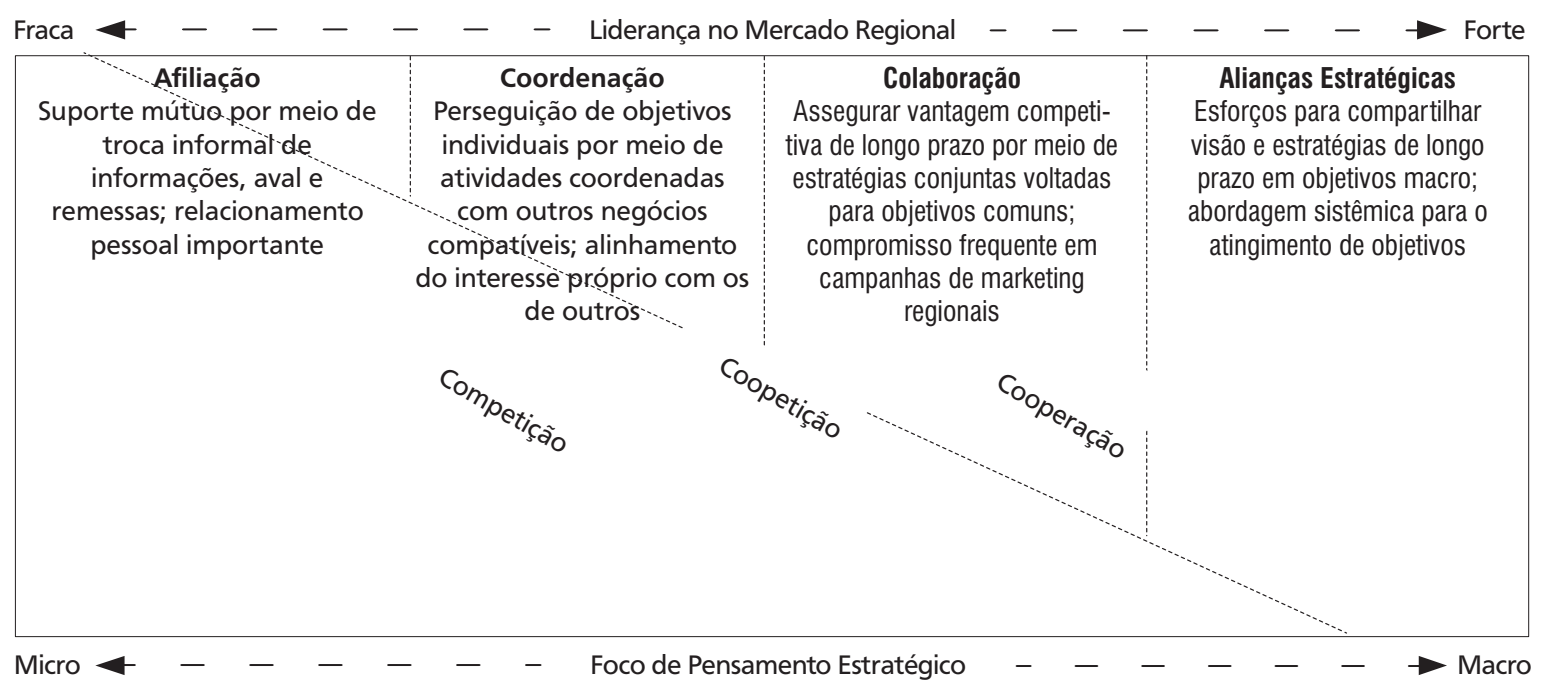

Figura 1 - Configuração dos relacionamentos

Fonte: Adaptado de WANG; KRAKOVER, 21008.

Nessa mesma linha, Brandenburger e Nalebuff (1997) definem a palavra coopetição (cunhada originalmente por Ray Noorda) como sendo uma abordagem revolucionária que combina cooperação e competição simultaneamente. Contudo, na perspectiva da coopetição, na competição o foco concentra-se em estratégias de apropriação de valor enquanto na cooperação o foco está nas estratégias coletivas para a geração de valor (GNYAWALI; MADHAVAN, 2001). Metaforicamente, a coopetição é uma atividade na qual duas ou mais empresas concorrentes cooperam para preparar um bolo maior (criar valor) e, fundamentalmente, competem por fatias maiores na hora dividi-lo (capturar valor).

A estratégia de coopetição é um conceito multidimensional e multifacetado que assume diferentes formas e requer múltiplos níveis de análise, pois reúne aspectos econômicos e sociais relacionados com a interdependência interorganizacional. Isto implica dizer que as empresas podem interagir adversariamente devido a interesses conflitantes e, ao mesmo tempo, cooperativamente, devido a interesses comuns (BENGTSSON; KOCK, 2000).

Chin, Chan e Lam (2008) identificaram uma série de fatores críticos de sucesso por meio de uma extensa revisão de literatura sobre o assunto. A hierarquia proposta consiste em quatro níveis e três categorias ao longo dos quais fatores e subfatores formam o modelo hierárquico da estratégia de coopetição, mostrada no Quadro 3.
Neste modelo, o comprometimento da gerência é tido como condição necessária para qualquer iniciativa empresarial de sucesso e reflete o nível de apoio dos gerentes para implementar a coopetição, sem a qual não poderá existir. 0 papel da liderança está em criar, propagar e sustentar os valores organizacionais que guiam a organização por meio de atividades coordenadas para alcançar a excelência. Os compromissos de longo prazo incluem também os compromissos estabelecidos com os concorrentes, tanto para criar sinergias, como para corrigir eventuais rumos estratégicos. $\mathrm{E}$ a aprendizagem organizacional também é crítica, uma vez que o processo de coopetição é complexo e exige que as empresas gerem, interpretem e distribuam conhecimento, promovendo a motivação e o envolvimento dos empregados.

0 desenvolvimento do relacionamento refere-se às boas relações que devem ser construídas entre os coopetidores. Assim, o desenvolvimento da confiança por meio do estabelecimento de objetivos comuns e da adaptação mútua das culturas organizacionais torna-se fundamental. Paralelamente, o risco e o conhecimento devem ser igualmente compartilhados entre as organizações, minimizando possíveis perdas e potencializando a geração de valor para ambas.

E para que tudo funcione, não só a coopetição em si, mas as duas dimensões anteriores do modelo hierárquico, a comunicação deve ser gerenciada sistemicamente por meio de planejamento, implementação, monitoramento e revisão constantes de todos os canais de comunicação, não só para a 
Quadro 3 - Modelo hierárquico da estratégia de coopetição

Nível 1: Objetivo

Nível 2:

Categoria de

Fatores

Nível 3: Fatores

Nível 4: Subfa-

tores

\begin{tabular}{|c|c|c|}
\hline \multicolumn{3}{|c|}{ Coopetição Bem-Sucedida } \\
\hline Comprometimento da & Desenvolvimento do & Gerenciamento da \\
\hline Gerência & Relacionamento & Comunicação \\
\hline 1.1 Liderança da gerência & 2.1 Desenvolvendo a Confiança & 3.2 Sistema de Informações \\
\hline 1.1.1 Visão e Missão & 2.1.1 Objetivos Comuns & de Suporte \\
\hline 1.1.2 Política e Estratégia & 2.1.2 Adaptação Mútua da & 3.1.1 Troca de Dados \\
\hline 1.1.3 Alocação de Recursos & Cultura Organizacional & 3.1.2 Coordenação Efetiva \\
\hline 1.2 Compromisso de & 2.2 Compartilhamento do & 3.2 Sistema de Gerenciamento \\
\hline Longo Prazo & Risco e Conhecimento & de Conflitos \\
\hline 1.2.1 Adaptar Forças e & 2.2.1 Identificação do & 3.2.1 Processo de Resolução \\
\hline Fraquezas Mútuas & Conhecimento & de Conflitos \\
\hline 1.2.2 Acordos de Longo Prazo & 2.2.2 Compartilhamento Efetivo & 3.2.2 Monitoramento de \\
\hline \multirow[t]{3}{*}{ 1.2.3 Revisões Periódicas } & do Conhecimento & Conflitos e Melhorias \\
\hline & 2.2.3 Compartilhamento & \\
\hline & Efetivo do Risco & \\
\hline \multicolumn{3}{|l|}{ 1.3 Aprendizagem } \\
\hline \multicolumn{3}{|l|}{ Organizacional } \\
\hline \multicolumn{3}{|l|}{ 1.3.1 Motivação Organizacional } \\
\hline \multicolumn{3}{|l|}{ 1.3.2 Participação dos } \\
\hline Funcionários & & \\
\hline
\end{tabular}

Fonte: adaptado de CHIN; CHAN; LAM, 2008.

troca de informações em si, como para a resolução de conflitos.

Uma vez que a implementação da estratégia de coopetição não pode ser realizada independentemente de seu conteúdo nem do contexto geral do ambiente em que as empresas envolvidas operam, a RBV pode ser vista como uma extensão lógica da coopetição uma vez que a sua lógica reconhece a importância estratégica do fenômeno comportamental e social que permite que as organizações escolham e adotem suas estratégias (BARNEY; ZAJAC, 1994).

\section{Discussão}

Conforme Meyer, Tsui e Hinings (1993), várias dimensões de ambientes, indústrias, tecnologias, estratégias, estruturas, culturas, ideologias, grupos, membros, processos, práticas, crenças e resultados podem ser agrupadas em configurações, as quais podem ser representadas em tipologias desenvolvidas conceitualmente ou taxonomias derivadas de forma empírica. Dessa forma, os autores citados explicam que os configuracionistas tentam explicar como a ordem emerge da interação das partes da organização a partir de uma visão holística, não linear e que oscila entre o equilíbrio e o desequilíbrio. Essa visão culmina para o entendimento de que nenhuma abordagem estratégica deve funcionar corretamente, se a mesma não estiver circunscrita em padrões apropriados e coerentes de processos e estruturas organizacionais. Assim, essa visualização mais ampla da organização por meio das classificações (tipologias e taxonomias) viabiliza a identificação de grupos homogêneos, os quais, de acordo com McKelvey (1978), são benéficos para a ciência organizacional no sentido de que o estudo de populações mais restritas (e mais adequadamente descritas) têm implicações mais importantes do que descobertas marginais generalizadas a uma população mais ampla.

A abordagem das configurações, portanto, indica que a maioria dos grupos de firmas tende a ser dirigida por temas centrais que alinham aspectos de estratégia, estrutura, cultura e processo. Isto desencadeia o entendimento de que os configuracionistas devem tentar entender melhor os correquisitos das diferentes estratégias genéricas ou recursos. De tal modo, a análise competitiva (MBV) poderia atentar-se às configurações mais bem sucedidas de táticas competitivas, habilidades e recursos organizacionais, sistemas 
de apoio à decisão e mecanismos de coordenação. Já a RBV poderia ser desenvolvida a partir da observação dos relacionamentos entre os recursos, estratégias competitivas, mecanismos de aprendizado e condições de mercado (MILLER, 1999). Esse autor avança propondo que, além das tipologias e taxonomias, as configurações podem também ser percebidas como uma qualidade ou propriedade que varia entre as organizações. Nesse sentido, as configurações podem ser definidas como o grau em que os elementos da organização são orquestrados e conectados por um tema central.

Essa concepção, portanto, conecta-se com a questão da vantagem competitiva, pois, de acordo com Miller (1999), o ponto fulcral não é a posse, mas a articulação dos recursos, que provê os requisitos para a consecução de vantagem competitiva, o que eleva a importância da noção de complementaridade. Uma conclusão que se consegue com a observação dessa discussão é que um alto grau de configuração pode resultar em uma série de vantagens sobre seguintes pontos: sinergia, clareza de direção e coordenação, dificuldade de imitação, competência distintiva, comprometimento, velocidade e economia. Entretanto ao mesmo tempo em que um alto grau de configuração torna a organização mais estreitamente focada e internamente coerente (MILLER, 1990; 1993), também a expõe ao perigo de torná-la exacerbadamente simples, ou seja, muito dominada pela única visão de mundo, dirigida por uma única abordagem ou função (MILLER; CHEN, 1996). A configuração excessiva pode indicar que os recursos são preponderantemente direcionados para uma atividade em particular. Outro exemplo é a adoção de critérios muito rígidos de admissão e promoção.

Consciente dessas possibilidades, Miller (1999) conclui que boa configuração é aquela que permite procedimentos de reavaliação e, até mesmo, de reconfiguração. Para complementar, esse autor expõe que o nível apropriado de configuração depende do ambiente da organização, sendo que, conforme Lawrence e Lorsch (1967), quanto mais dinâmico e incerto o mesmo for, mais fracamente acoplados devem ser os elementos da organização. Por fim, Miller (1999) sugere que, para avaliar o grau de configuração de uma organização, deve-se examinar: seu foco ou simplicidade, o ajuste entre seus elementos e a amplitude de elementos ou partes subsumidas por um tema central.

Restringindo a discussão para o contexto dos APLs, reconhece-se que normalmente os mesmos abrigam grande número de pequenas empresas. Nesse sentido, a definição das variáveis deve levar essa questão em consideração. Mugler (2004) sugere quatro grupos de variáveis: o ambiente da firma, os recursos da firma, a personalidade do empreendedor e o sistema de gestão adotado. Sua justificativa para esses grupos de variáveis é a de que um determinado tipo de empreendedor equipado com certos recursos pode ser forçado a retirar-se em um contexto incerto ou desfavorável enquanto um tipo diferente de empreendedor com um diferente conjunto de recursos pode ser bem sucedido nesse mesmo contexto. Nesse sentido, os imperativos de Miller (1987), combinados com a tipologia de recursos de Greene, Brush e Brown (1997) mensurada a partir da concepção de Wang e Krakover (2008), parecem representar adequadamente este contexto.

Observando os Quadros 4 e 5, a partir das tipologias derivadas dos imperativos e dos possíveis estados de relacionamento em relação aos recursos, obtém-se, teoricamente, um elevado número de configurações possíveis. Por exemplo, uma empresa cujo imperativo é empreendedor, pode combinar cinco diferentes estados de relacionamentos com relação aos cinco recursos principais (recursos humanos, físicos e organizacionais em colaboração com outras empresas, sociais por meio de alianças estratégicas e financeiros com relacionamento nulo, se depender apenas de recursos financeiros próprios). Nesse sentido, podem-se estudar as possíveis configurações dos imperativos em relação às configurações dos relacionamentos, sem contar a possibilidade de acrescentar outras variáveis ao estudo, como o desempenho, por exemplo.

Mas a adoção desses construtos para o estudo de empresas para as quais este ensaio se dirige pode sofrer complicações, o que demanda uma reflexão adicional. Nesse sentido, uma questão relevante que Maciel, Reinert e Camargo (2008) levantam é que, no espectro das pequenas organizações, os imperativos originalmente propostos por Miller (1987) talvez não sejam capazes de diferenciá-las significativamente porque os tipos organizacionais não podem ser dissociados das características de seu contexto ambiental. Em vista disso, os autores acima citados sugerem a criação de novos imperativos que tenham condições de prover as bases para a descoberta de configurações distintas de pequenas empresas que, por sua vez, consigam explicar parte da heterogeneidade do desempenho organizacional. Assim, os mesmos autores propõem (e testam 
Quadro 4 - Tipologias derivadas dos imperativos

\begin{tabular}{|c|c|c|c|c|}
\hline \multicolumn{5}{|c|}{ Imperativos (MILLER, 1987) } \\
\hline Ambiente & Estrutura & Liderança & Estratégia & \\
\hline Mecanicista & Simples & Simples & Prospectora & Liderança no custo total \\
\hline \multirow[t]{4}{*}{ Orgânico } & Burocracia Mecanizada & Empreendedora & Defensora & Diferenciação \\
\hline & Burocracia Profissional & & Analítica & Enfoque \\
\hline & Divisionalizada & & Reativa & \\
\hline & Adhocracia & & & \\
\hline Burns e Stalker (1961) & Mintzberg (1979) & Mintzberg (1979; 1973) & Miles e Snow (1978) & Porter (1980) \\
\hline
\end{tabular}

Fonte: Dados da pesquisa.

Quadro 5 - Relacionamentos em relação à classificação de recursos

\begin{tabular}{llllll}
\hline Autores & & & Relacionamentos & \\
\hline $\begin{array}{l}\text { Greene, Brush e } \\
\text { Brown (1997) }\end{array}$ & Humanos & Sociais & Físicos & Organizacionais & Financeiros \\
& Nulo & Nulo & Nulo & Nulo & Nulo \\
& Afiliação & Afiliação & Afiliação & Afiliação & Afiliação \\
$\begin{array}{l}\text { Wang e Krakover } \\
(2008)\end{array}$ & Coordenação & Coordenação & Coordenação & Coordenação & Coordenação \\
& Colaboração & Colaboração & Colaboração & Colaboração & Colaboração \\
& $\begin{array}{l}\text { Alianças Estraté- } \\
\text { gicas }\end{array}$ & $\begin{array}{l}\text { Alianças Estraté- } \\
\text { gicas }\end{array}$ & $\begin{array}{l}\text { Alianças Estraté- } \\
\text { gicas }\end{array}$ & $\begin{array}{l}\text { Alianças Estraté- } \\
\text { gicas }\end{array}$ & $\begin{array}{l}\text { Alianças Estraté- } \\
\text { gicas }\end{array}$ \\
\hline
\end{tabular}

Fonte: Dados da pesquisa.

empiricamente) três imperativos distintos: comportamento empreendedor; locus de controle; e capacidades organizacionais. Essa preocupação parece concatenar-se às assunções de Mugler (2004), o qual, conforme já foi especificado acima, sugere quatro grupos de variáveis para o contexto das pequenas empresas (ambiente, recursos, personalidade do empreendedor e sistema de gestão).

Entretanto, mesmo concordando que os imperativos de Miller (1987) possam encontrar dificuldades para distinguir pequenas organizações, se estiverem essencialmente em um mesmo ambiente e/ou se pertencerem a uma determinada atividade econômica específica, deve-se notar que a replicação de estudos, principalmente para testar tipologias e/ou taxonomias em outros contextos precisam ser contextualizadas em relação a esses mesmos imperativos. A razão para esta discussão é a de que os imperativos de Miller (1987) não precisam (e provavelmente não devam) ser substituídos, mas complementados com novos imperativos adequados ao contexto que se está estudando. Essa concepção enquadra-se na ideia de que a abordagem das configurações vincula-se a uma teorização de médio alcance, a qual evita a busca de grandes generalizações, mesmo porque a complexidade e a conseguinte diversidade das organizações provavelmente não permitam que se estabeleçam explicações universais para o funcionamento das mesmas.

No contexto dos APLs, uma possibilidade de pesquisa que parece fazer muito sentido é o estudo das configurações em dois níveis distintos: um mais 
amplo, que envolve os atributos do próprio APL e um mais profundo, atingindo as organizações a ele circunscritas individualmente. Como os APLs têm características distintas, inclusive por questões de seu próprio ciclo de vida, certamente os imperativos de Miller (1987) teriam boas possibilidades de distingui-los, pois ao mesmo tempo em que os ambientes de diversos APLs podem ser distintos, essencialmente em razão da indústria a que pertencem; as estruturas, aspectos da liderança e as estratégias podem igualmente ser diferentes, dependendo do nível de maturação e de governança do próprio APL. Em síntese, o que se propõe a dizer neste ponto é que, embora haja argumentos plausíveis para acreditar que pequenas empresas de um dado APL apresentem configurações parecidas, talvez até mesmo enquadrando-as em uma mesma gestalt, talvez se deva reconhecer a possibilidade de pequenas empresas pertencentes a diferentes APLs apresentarem configurações igualmente distintas. Assim, mesmo que um conjunto de imperativos não seja capaz de distinguir as empresas no interior de um APL, certamente o seja para caracterizar o APL, ou até mesmo para distingui-los dos demais no caso de estudos que abarquem mais de um. Ademais, mesmo que o estudo se restrinja a um APL específico, a sua devida caracterização pelos imperativos de Miller (1987) é expediente profícuo para a comparação de estudos de APLs diferentes. Isso vai de encontro com a própria essência da abordagem das configurações, que assume um protocolo de não linearidade e de influências multidirecionais. Por outro lado, não se pode determinar de maneira cabal que os imperativos de Miller (1987) não distingam quaisquer tipos de empresas de pequeno porte. A questão levantada é a de que, como há chances de haver, no interior do APL, um percentual elevado de organizações similares, seus imperativos talvez sejam mais direcionados à caracterização do próprio APL, e não das empresas individualmente, embora não se possa descartar essa possibilidade.

A proposição, portanto, que se pretende lançar é a de que a explicação do fenômeno da coopetição demanda dois momentos antecedentes: a caracterização do APL por meio dos imperativos de Miller (1987), ou seja, ambiente, estrutura, liderança e estratégia; a caracterização das empresas do ponto de vista individual, a partir dos novos imperativos sugeridos por Maciel, Reinert e Camargo (2008), que envolvem comportamento empreendedor, locus de controle externo e capacidades organizacionais. 0 modelo a ser considerado, assim, direciona os imperativos de Miller (1987) mais fortemente à caracterização geral do APL, sem a pretensão, embora possível, de gerar um número plural de configurações. Na sequência, os imperativos sugeridos por Maciel, Reinert e Camargo (2008) assumem esse papel de prover as bases para a distinção das empresas circunscritas a um dado APL. Por fim, observa-se o fenômeno da coopetição a partir da proposição de Wang e Krakover (2008) em relação a cada tipo de recurso, conforme Greene, Brush e Brown (1997). Dessa forma, esse encadeamento sugerido permitiria que se estudassem os efeitos de um conjunto de imperativos (do APL) sobre outro conjunto de imperativos (das firmas) e desse último conjunto sobre o fenômeno da coopetição. Vale destacar que, de acordo com essa proposta, os dados referentes a todos os imperativos são coletados no nível organizacional, mas como um subgrupo dos mesmos talvez não consiga gerar configurações distintas no interior do APL, os mesmos ficariam a cargo de contextualizar o próprio APL de forma geral.

\section{Considerações finais}

A discussão trazida pelo presente ensaio fortalece a noção de que toda estratégia competitiva possui elementos racionais e outros irracionais e imprevistos. Estratégias reativas e o foco nos pontos fortes apenas, tanto de uma empresa individual como de um APL não são suficientes para vencer os desafios dos mercados atuais. Assim, de acordo com a articulação teórica realizada, foi possível encontrar indicativos de que o status atual da perspectiva das configurações explica o fenômeno da coopetição em APLs apenas parcialmente, uma vez que a literatura consultada, diferentemente das proposições aqui tratadas, restringe-se a apenas um nível de observação, qual seja, as organizações do ponto de vista individual.

Há que se considerar que as organizações de per si possuem características próprias e modelos de gestão característicos. Essas diferenças individuais se conservam, mesmo quando se associam com outras para a formação de APLs, o que faz, por conseguinte, que cada APL seja ainda mais característico e difícil de ser enquadrado em um conjunto de tipologias e/ ou taxonomias limitado. Como esses dois níveis (a organização e o APL) estão inscritos no ambiente da tarefa, se a abordagem for ampliada para o ambiente geral, será possível notar ainda, que a natureza da 
formação de tais arranjos ainda pode ter características particulares ligadas aos cenários político, econômico e tecnológico que afetam tanto as empresas individualmente como em conjunto.

Além disso, nenhum APL parece perseguir necessidades permanentes, não porque não possuam estratégias de longo prazo, mas especialmente porque a dinâmica dos mercados globais não permite, o que se concatena aos pressupostos da abordagem das configurações, que também se incumbe de observar o comportamento organizacional do ponto de vista longitudinal, como um processo de transformação. A vantagem competitiva está atrelada à inovação e as empresas e suas alianças seguem esse ritmo de mudança para competir com grandes players e conservar clientes e mercados. Dessa forma, a orientação estratégica, no caso específico dos APLs, tende a ser eminentemente situacional.

O esforço envidado no presente ensaio buscou argumentar que a MBV e a RBV não necessariamente precisam ser observadas como abordagens concorrentes, mas sim complementares, conforme a discussão realizada na seção precedente. Entretanto vale destacar que as possibilidades levantadas não devem ser interpretadas como uma proposta pronta e que não mereça aprofundamentos ulteriores. Esse exercício, portanto, pode até mesmo suscitar a criação de outras tipologias a serem utilizadas posteriormente em estudos de natureza teórico-empírica. Outro fator importante sobre a discussão ora realizada vincula-se ao próprio fenômeno ao qual se dirigiu este ensaio. A coopetição não precisa e não deve restringir-se como variável dependente, a mesma pode ser incorporada a estudos que almejem observar o resultado do exercício deste fenômeno, como o desempenho, conforme já foi argumentado.

Contudo como este trabalho suscita mais perguntas do que oferece respostas, fica a sugestão para que trabalhos futuros procurem estudar o fenômeno a partir desses três níveis sugeridos, para melhor compreender como empresas combinam seus recursos para atender aos requisitos das necessidades dos mercados, consoantes aos efeitos das forças ambientais dos setores em que operam essas empresas, ou seja, agrupando variáveis oriundas tanto da MBV, como na RBV. Nesse sentido, a abordagem das configurações aparece como um encaminhamento que viabiliza esse exercício.

\section{Referências}

AMATO NETO, J. Redes de cooperação produtiva e clusters regionais: oportunidades para as pequenas e médias empresas. São Paulo: Atlas: 2000.

BARNEY, J. Firm resources and sustained competitive advantage. Journal of Management, v. 17, n. 1, p. 99-120, 1991.

BARNEY, J. B.; ZAJAC, E. J. Competitive organizational behavior: toward an organizationally-based theory of competitive advantage. Strategic Management Journal, v. 15, n. 1 , p. $5-9,1994$.

BENGTSSON, M.; KOCK, S. Coopetition' in business networks - to cooperate and compete simultaneously. Industrial Marketing Management, v. 29, n. 5, p. 411426, 2000.

BRANDENBURGER, A. J.; NALEBUFF, B. J. Co-opetition. Doubleday: New York, 1997.

BRUSH, C. G.; GREENE, P. G.; HART, M. M. From initial idea to unique advantage: the entrepreneurial challenge of constructing a resource base. The academy of Management Executive, v. 15, n. 1, p. 64-78, 2001.

CHIN, K. S.; CHAN, B. L.; LAM, P. K. Identifying and prioritizing critical success factors for coopetition strategy. Industrial Management \& Data Systems, v. 108, n. 4, p. 437-454, 2008.

DOZ, Y. Technology partnerships between larger and smaller firms: some critical issues. International Studies of Management and Organization, v. 17, n. 4, p. 31-57, 1988.

GINSBERG, A.; LARSEN, E.; LOMI, A. Entrepreneurship in context: strategic interaction and the emergence of regional economies. In: SCHOONHOVEN, C. B.; ROMANELLI, E. (Ed.). The entrepreneurship dynamic: the origins of entrepreneurship and the evolution of industries. Palo Alto: Stanford University Press, 2002.

GNYAWALI, D. R.; MADHAVAN, R. Cooperative networks and competitive dynamics: a structural embeddedness perspective. Academy of Management Review, v. 26, n. 3, p. 431-445, 2001.

GRANT, R. M. The resource-based theory of competitive advantage: implications for strategy formulation. California Management Review, v. 33, n. 3, p. 114-135, 1991. 
GREENE, P. G.; BRUSH, C. G.; BROWN, T. Resources in small firms: an exploratory study. Journal of Small Business Strategy, v. 8, n. 2, p. 25-40, 1997.

KOZA, M. P.; LEWIN, A. Y. The co-evolution of strategic alliances. Organizational Science, v. 9, n. 3, p. 255-264, 1998.

KUHN, T. S. A estrutura das revoluções científicas. São Paulo: Perspectiva, 2000.

LAWRENCE, P. R.; LORSCH, J. W. Organizational environment. Boston: Harvard Business School Press, 1967.

MACIEL, C. O.; REINERT, M.; CAMARGO, C. Configurações estratégicas e desempenho organizacional: em busca de novos imperativos. Rebrae, Curitiba, v. 1, n. 2, p. 199-212, maio/ago. 2008.

MAKHIJA, M. Comparing the resource-based and marketbased views of the firm: empirical evidence from Czech privatization. Strategic Management Journal, v. 24, n. 5, p. 433-451, 2003.

MARSHALL, A. Princípios de economia: trabalho introdutório. São Paulo: Abril Cultural, 1982.

MCKELVEY, B. Organizational systematic: taxonomies lessons from biology. Management Science, v. 24, n. 13, p. 1428-1440, 1978.

MEYER, A. D.; TSUI, A. S.; HININGS, C. R. Configurational approaches to organizational analysis. Academy of Management Journal, v. 36, n. 6, p. 1175-1195, 1993.

MILES, R. E.; SNOW, C. C. Organizational strategy, structure and process. New York: McGraw-Hill, 1978.

MILLER, D. The genesis of configuration. Academy of Management Review, v. 12, n. 4, p. 686-701, 1987.

MILLER, D. Organizational configurations: cohesion, change and prediction. Human Relations, v. 43, n. 8, p. 771-789, 1990.

MILLER, D. The architecture of simplicity. Academy of Management Review, v. 18, n. 1, p. 116-138, 1993.

MILLER, D. Notes on the study of configurations. Management International Review, v. 39, n. 2, p. 27-39, 1999.
MILLER, D.; CHEN, M. J. The simplicity of competitive repertories: an empirical analysis. Strategic Management Journal, v. 17, n. 6, p. 419-439, 1996

MILLER, D.; MINTZBERG, H. The case for configuration. In: MORGAN, G. (Org.). Beyond method: strategies for social research. London: Sage Publications, 1985.

MUGLER, J. The configuration approach to the strategic management of small and medium- sized enterprises. In: BUDAPEST POLYTECHNIC JUBILEE CONFERENCE SCIENCE IN ENGINEERING, ECONOMICS AND EDUCATION, 2004, Budapest. Proceedings... Budapest: BMF, 2004.

PARKER, H. Interfirm collaboration and the new product management. Industrial Management \& Data Systems, v. 100, n. 6 , p. 255-260, 2000.

PENROSE, E. The theory of the growth of the firm. London: Basil Blackwell, 1959.

PORTER, M. E. Competitive strategy: techniques for analyzing industries and competitors. New York: The Free Press, 1980.

PORTER, M. E. The competitive advantage: creating and sustaining superior performance. New York: Free Press, 1985.

PRAHALAD, C. K.; HAMEL, G. The core competence of corporation. Harvard Business Review, v. 68, n. 3, may/ june, 1990.

RING, P. S.; VAN DE VEN, A. H. Developmental processes of cooperative interorganizational relationships. Academy of Managemen Review, v. 19, n. 1, p. 90-118, 1994.

ROBINSON JUNIOR, R. B.; PEARCE, J. A. Research thrusts in small firm strategic planning. Academy of Management Journal, v. 9, n. 1, p. 128-137, 1984.

RUMELT, R. P. Towards a strategic theory of the firm. In: LAMB, R. B. (Ed.). Competitive strategic management Englewood Clifs: Prentice-Hall, 1984.

SCHMITZ, H. On the clustering of small firms. IDS Bulletin, v. 23, n. 3, p. 64-68, 1992. 
SCHMITZ, H.; MUSYCK, B. Industrial districts in Europe: policy lessons for developing countries? Discussion paper 324. Brighton: University of Sussex - Institute of Development Studies, 1993.

WANG, Y.; KRAKOVER, S. Destination marketing: competition, cooperation or coopetition? International Journal of Contemporary Hospitality Management, v. 20, n. 2, p. 126-141, 2008.

WELSH, J. A.; WHITE, J. F. A small business is not a little big business. Harvard Business Review, v. 59, n. 4, p. 18-32, 1981.

WERNERFELT, B. A resource-based view of the firm. Strategic Management Journal, v. 5, n. 2, p. 171-180, 1984.

Recebido: 26/09/2011

Received: 09/26/2011

Aprovado: 24/07/2012

Approved: 07/24/2012 